\title{
Free Paper
}

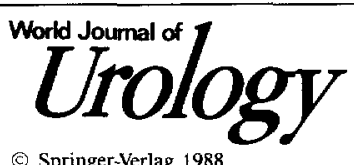

(C) Springer-Verlag 1988

\section{Incidence, pathophysiology and treatment of prolonged erections}

\author{
C.G. Stief ${ }^{1}$, W. Bähren ${ }^{2}$, H. Gall ${ }^{3}$, and W. Scherb ${ }^{4}$
}

Departments of ${ }^{1}$ Urology, ${ }^{2}$ Radiology, ${ }^{3}$ Dermatology and ${ }^{4}$ Neurology and Psychiatry, BWK, Academic Hospital of the University of Ulm, FRG

Summary. Prolonged erections (pharmacologically induced erections over 6 hours) are the most inconvenient side effects encountered in the diagnosis and therapy of erectile dysfunction with intracavernous injection of vasoactive drugs. Out of a total of 29 prolonged erections, 26 were seen after diagnostic use in 300 patients and 3 after therapeutic application in more than 4800 protocolled autoinjection of a standardized vasoactive solution (papaverine hydrochloride $15 \mathrm{mg} / \mathrm{ml}$ and phentolamine mesylate $0.5 \mathrm{mg} / \mathrm{ml}$ ). In 25 of these 29 prolonged erections intracavernous injections of the alpha-receptor stimulant metaraminol was done and led to flaccidity in all cases. Another patient with a papaverine-induced erection lasting $26 \mathrm{~h}$ did not respond to intracavernous metaraminol and required puncture and aspiration; he lost spontaneous erectability and cavernosal response to vasoactive drugs. Metaraminol was also injected intracavernosally in a further 32 patients with pharmacologically induced full erections: flaccidity was obtained in all patients.

Since intracavernous injection of vasoactive substances has proven easy to manage, safe and effective in the diagnosis and therapy of erectile dysfunction, it has found widespread use in patients with erectile failure $[1,2$, $9-13]$. However, as an untoward side effect, prolonged erection (pharmacologically induced erection lasting over $6 \mathrm{~h})$ has been observed with increasing frequency $[2,3$, $9-13]$. At first Brindley reported prolonged erections in 16 patients responding to intracavernous administration of phenoxybenzamine, which ceased spontaneously after $22 \mathrm{~h}$ [2]. Later he mentioned another patients with prolonged erections lasting up to $40 \mathrm{~h}$. Every patient was treated successfully with intracavernous injection of the alpha-receptor stimulant metaraminol [3]. Zorgniotti reported a prolonged erection in 1 of 65 patients after intracavernous autoinjection of papaverine-phentolamine [13]. He recommended treatment with puncture and aspiration. We report our experience with incidence,

Requests for reprints and correspondence to: Dr. C. G. Stief, Abteilung für Urologie, Unikliniken, Hugstetterstrasse 55, D-7800 Freiburg pathophysiology and treatment of prolonged erections in the diagnosis and treatment of erectile dysfunction with vasoactive drugs. The control of this serious and frequent side effect is an indispensable requirement for therapy with intracavernous injection of vasoactive drugs.

\section{Patients and methods}

The intracavernous injection of the alpha-receptor stimulant metaraminol was used to counteract 1 TUR- and 58 pharmacologically induced erections. The patients were divided into 6 groups as described below, with 10 healthy men serving as controls (Table 1).

To prevent hematomas as a result of puncture, aspiration or injection, a swab was pressed for $5 \mathrm{~min}$ on the site where the needle had penetrated. Blood pressure, pulse rate and ECG were monitored closely over $30 \mathrm{~min}$ in each patient of all 6 groups. Changes in arterial inflow and blood gases were documented by Doppler tests and blood gas analyses performed on 12 patients.

Group I (control group)

Metaraminol was used in a reference group of 10 potent young men (average age 24 years) to interrupt a complete 2 -h erection induced by phentolamine mesylate $0.25 \mathrm{mg}$ and papaverine hydrochloride $7.5 \mathrm{mg}$.

Group 2 (prolonged erection during diagnosis)

Between February 1985 and January 1987, 300 patients with erectile dysfunction underwent multidisciplinary examinations at the BWK-hospital in Ulm to elucidate the origin of their erectile failure. Due to the fact that vasoactive substances were used for diagnosis, patients with arterio-occlusive disease (AOD), starting with stage III, cardiac dysrhythmia, severe liver or kidney diseases or patients older than 65 years were excluded because adverse reactions were anticipated.

Table 1. A total of 63 erections treated in 61 patients by either aspiration and puncture (4 patients of group 2) or intracavernous injection of metaraminol (58 patients). Patients were assigned to 6 groups according to their etiology

\begin{tabular}{llll}
$\begin{array}{l}\text { Group } \\
\text { No. }\end{array}$ & $\begin{array}{l}\text { Patients } \\
\text { No. }\end{array}$ & $\begin{array}{l}\text { Erections } \\
\text { No. }\end{array}$ \\
\hline 1. & Control group & 10 & 10 Full erections \\
2. & Diagnostic injections & 24 & 26 Prolonged erections \\
3. & Auto-injection therapy & 3 & 3 Prolonged erections \\
4. & Impotent patients & 20 & 20 Full erections \\
5. & Potent patients & 3 & 3 Prolonged erections \\
6. & TUR-P & 1 & 1 Full erection \\
\hline
\end{tabular}


After obtaining a comprehensive history with the aid of a questionnaire, the following tests were performed: physical examination, blood tests including fats, glucose tolerance and hormones (testosterone, prolactin; if applicable FSH, LH), sexual anamnesis and psychometry (MMPI: Minnesota Multiphasic Psychoinventory FPI: Freiburger Psychoinventory), bulbo-cavernosus reflex (BCR) latency and somatosensory-evoked potentials (SSEP), ultrasonography of abdomen and large vessels, Doppler and penile-brachial index (PBI) [5]. Selective angiography of the pelvis and penis [4] was performed on 59 patients, dynamic cavernosography on 94 . Subsequently, i.c. pharmaacotesting was done.

After informed consent was obtained, each patient received an injection of papaverine hydrochloride $(7.5 \mathrm{mg})$ and phentolamine mesylate $(0.25 \mathrm{mg}$ ) in the right proximal corpus cavernosum by means of a 26-gauge needle. In 24 of the 300 patients, intracavernous injection of this mixture led to prolonged erections (persisting $6 \mathrm{~h}$ ), associated with painful tension of the penile shaft in 3 cases (Table 1). Although only $3.7 \mathrm{mg}$ papaverine and $0.12 \mathrm{mg}$ phentolamine were injected the following day, another prolonged erection occurred in 2 of the 24 patients.

The first 4 cases of prolonged erection were treated by aspiration and lateral puncture of the proximal third of both corpora cavernosa using a 19-gauge needle. The other 20 patients were administered metaraminiol intracavernosally, the first 7 being injected with $2.5 \mathrm{mg}$ using a 26-gauge cannula, the remaining with $2.0 \mathrm{mg}$ in the right proximal corpus cavernosum. Previous aspiration of blood was omitted.

\section{Group 3 (prolonged erection during auto-injection therapy)}

During auto-injection therapy at home, only 3 patients reported the occurrence of 1 prolonged erection each, persisting for $6-12 \frac{1}{2} \mathrm{~h}$ (mean $=8 \mathrm{~h}$ ). A total of 4813 auto-injections were documented. The prolonged erections occurred despite individual dosing for induction of an erection of $30-90 \mathrm{~min}$ duration. In each of the 3 cases, the patient had self-injected a second dose after thinking the first injection was unsuccessful.

\section{Group 4 (interruption of erection due to injection of vasoactive} substances)

To unveil possible circulatory side effects of the intracavernous injection of metaraminiol, 20 patients with erectile dysfunction responding to the intracaverous injection of papaverine and phentolamine with a full erection were injected $2 \mathrm{mg}$ metaraminol intracavernosally following diagnostic injection (average dosage $13.5 \mathrm{mg}$ papaverine and $0.45 \mathrm{mg}$ phentolamine). Metaraminol was injected after half of the expected individual duration of erection $(72 \mathrm{~min})$. Each of these patients consented to this study.

\section{Group 5 (accidental prolonged erection in potent men)}

Two potent men ( 24 and 41 years) self-administered an intracavernosal injection of a vasoactive mixture ,in order to achieve greater satisfaction for the sex partner". Both men injected a solution of papaverine hydrochloride $(7.5 \mathrm{mg})$ and phentolamine mesylate $(0.25 \mathrm{mg})$ that had been supplied by other hospitals. The injections produced erections persisting for 6 and $18.5 \mathrm{~h}$ respectively. The second patient experienced painful tension of the penile shaft after $12 \mathrm{~h}$ of erection.

A third, 60-year-old, patient, capable of having normal coitus with full erections every 14 days, was injected papaverine hydrochloride $(30 \mathrm{mg})$ by his urologist. As there was no effect within $10 \mathrm{~min}$ after administration, another $30 \mathrm{mg}$ were injected and the patient was sent home with a complete erection. After $24 \mathrm{~h}$ he returned with a painful prolonged erection. At the office, intracavernous injection of $4 \mathrm{mg}$ mataraminol had no effect. After 2 more hours, he was admitted to our hospital with a palpable, complete, painful erection.

\section{Group 6 (erection during TUR)}

A 71-year-old patient with a history of unimpaired sexual potency and coronary heart disease was to undergo transurethral resection for benign prostatic hyperplasia (BPH). Introduction of the resectoscope caused an erection with palpable full rigidity persisting for $15 \mathrm{~min}$, which made transurethral resection impossible. In order to interrupt the erection, metaraminol $(2 \mathrm{mg})$ was injected in the right proximal corpus cavernosum.

\section{Results}

\section{Group I (control group)}

All 10 potent man exhibited complete flaccidity 9-22 $\min ($ mean $=13.1 \mathrm{~min})$ after intracavernous injection of metaraminol $(2 \mathrm{mg})$ in the right proximal corpus cavernosum. The ability to have spontaneous erections on the next day was not impaired.

\section{Group 2 (prolonged erection during diagnosis)}

In the first 4 prolonged erections aspiration of $210-400 \mathrm{ml}($ mean $=315 \mathrm{ml})$ of unclotted blood produced constant flaccidity in all cases. Residual spontaneous activity and the response to intracavernosal injection of vasoactive substances on the third day after puncture were unchanged as compared with the previous state, i.e., before the prolonged erection.

The following 22 prolonged erections subsided after intracavernous metaraminol $(2.5$ or $2.0 \mathrm{mg}$ ). Complete flaccidity was attained after $7-20 \mathrm{~min}$ (mean = $14.4 \mathrm{~min}$ ); the difference between the two doses was not statistically significant. The response to intracavernous injection of vasoacitve drugs on the next day was not impaired.

\section{Group 3 (prolonged erection during auto-injection therapy)}

Intracavernosal injection of metaraminol $(2.5 \mathrm{mg})$ in the rigth proximal corpus cavernosum did not reduce rigidity in any of the three patients. The erection did not subside

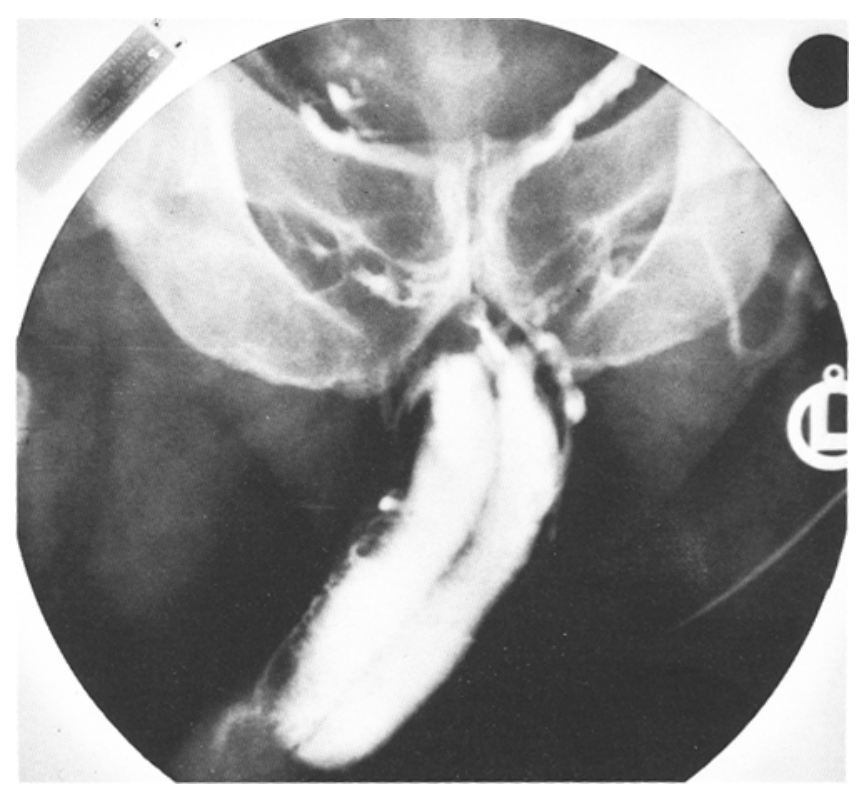

Fig. 1. Dynamic cavernosography $48 \mathrm{~h}$ after treatment of a 26-h prolonged erection by puncture and aspiration. Maintainanceflow $=148 \mathrm{ml} / \mathrm{min}$ 


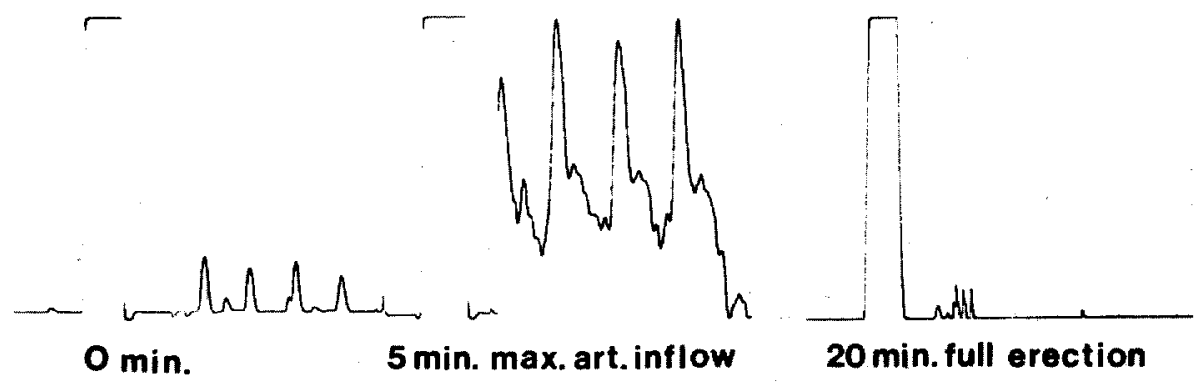

Fig. 2. Doppler sonography before, and 5 and $20 \mathrm{~min}$ after erection induced by vasoactive drugs
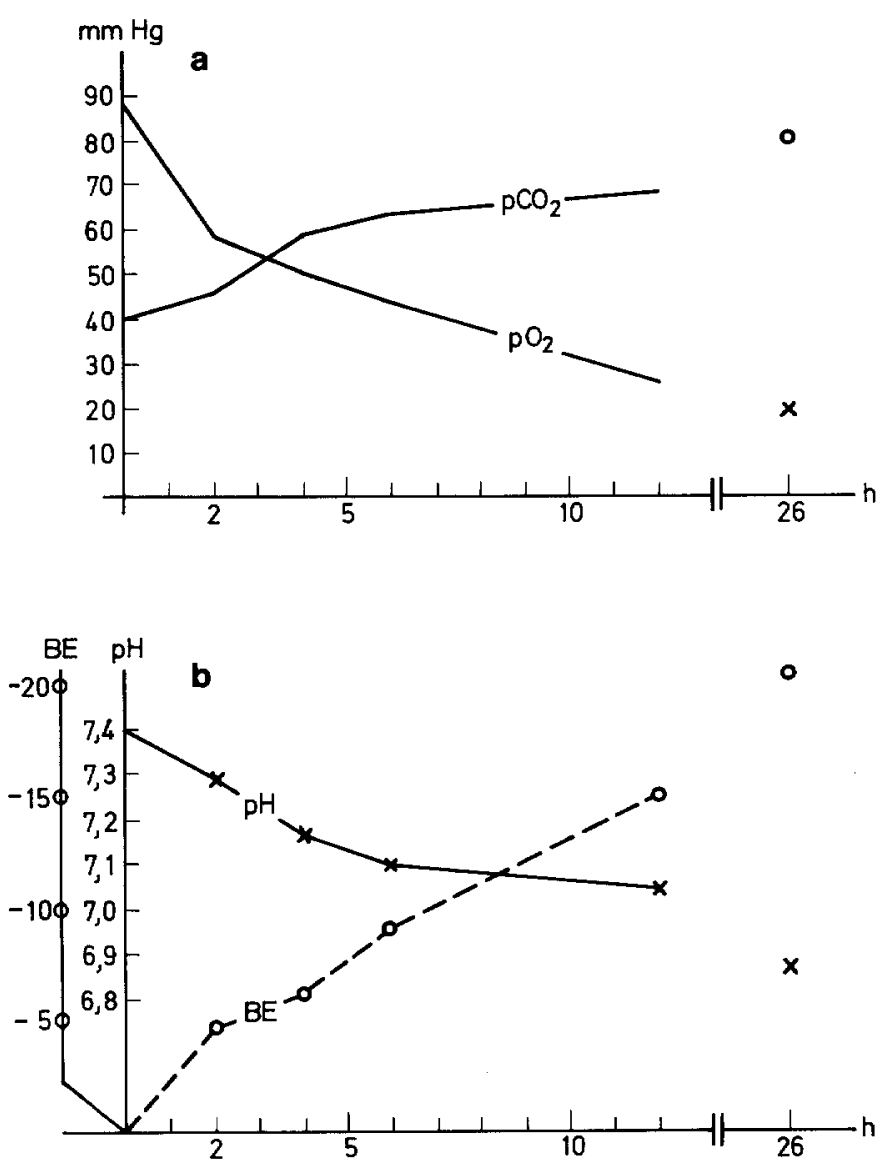

Fig. 3a, b. Intracavernous blood gas analysis performed in 12 patients with pharmacologically induced full erections. The analysis was done in 3 patients after $2 \mathrm{~h}$, in 3 patients after $4 \mathrm{~h}$, in 3 patients after $6 \mathrm{~h}$, in 2 patients after $12 \mathrm{~h}$ and in 1 patient after $26 \mathrm{~h}$. a With duration of the full erection, $\mathrm{pO}_{2}$ decreases and $\mathrm{pCO}_{2}$ increases significantly. b Simultaneous to the changes in Fig. $3 \mathrm{a}, \mathrm{pH}$ decreases and the negative base excess increases dramatically

until, $10 \mathrm{~min}$ later, $1 \mathrm{mg}$ of metaraminol was additionally injected into the proximal left corpus cavernosum. Complete flaccidity was attained ca. $15 \mathrm{~min}$ after the second injection.

\section{Group 4 (interruption of erection due to injection of vasoactive substances)}

Intracavernosal injection of metaraminol $(2 \mathrm{mg})$ in the right proximal corpus cavernosum caused complete flac- cidity within $3.5-12 \mathrm{~min}$ (mean $=7.7 \mathrm{~min}$ ) in all $20 \mathrm{pa}$ tients.

\section{Group 5 (accidental prolonged erection in potent men)}

In the first two subjects, the erection subsided after metaraminol $(2 \mathrm{mg})$ had been injected in the right proximal corpus cavernosum; flaccidity was attained after about $10 \mathrm{~min}$.

The third subject, who had received the papaverine dose twice had been administered an injection of metaraminol ( $4 \mathrm{mg}$ ) in the right corpus cavernosum by his urologist. As there was no apparent decrease in rigidity within $1 \mathrm{~h}$, he was referred to our hospital.

The blood gas analysis performed after $26 \mathrm{~h}$ of complete erection yielded a $\mathrm{pH}$ of $6.87, \mathrm{pO}_{2}$ of $19 \mathrm{mmHg}$, $\mathrm{pCO}_{2}$ of $73 \mathrm{mmHg}$ and a base excess of -25 . As the injection of metaraminol $(3 \mathrm{mg})$ in the left corpus cavernosum did not produce any decrease in rigidity within $15 \mathrm{~min}$, both corpora cavernosa were punctured with a 19-gauge cannula using an antibiotic for prophylaxis (Ceftacidin $2 \mathrm{~g}$ i.v.). Aspiration led to immediate detumescence; $520 \mathrm{ml}$ of dark, unclotted blood was withdrawn (the blood clotted in the kidney dish within $7 \mathrm{~min}$ ). Thereafter, the following blood gas values were obtained: pH 7.44, $\mathrm{pO}_{2} 77 \mathrm{mmHg}, \mathrm{pCO}_{2} 35 \mathrm{mmHg}$, base excess +1.0 . Before the cannulas were removed, metaraminol ( $2 \mathrm{mg}$ ) was injected into the right corpus cavernosum. No spontaneous erection occurred within the next $24 \mathrm{~h}$. Cavernosography showed pathologic venous outflow $48 \mathrm{~h}$ following puncture without any evidence of thrombotic obliteration of the venous drains (Fig. 1).

After 3 months, the patient reported complete loss of spontaneous full erectability. He did not respond to maximal doses $(3 \mathrm{ml})$ of a standardized vasoactive solution (papaverine hydrochloride $15 \mathrm{mg} / \mathrm{ml}$ and phentolamine mesylate $0.5 \mathrm{mg} / \mathrm{ml}$ ) with full erection.

\section{Group 6 (erection during TUR)}

Intracavernosal injection of metaraminol $(2 \mathrm{mg})$ led to complete flaccidity within $5 \frac{1}{2} \mathrm{~min}$. The ECG $3 \mathrm{~min}$ after injection showed atrial extrasystoles for about $140 \mathrm{sec}$, which did not call for treatment and ceased without therapy. During this time, the systolic blood pressure increased by $15 \mathrm{mmHg}$. 


\section{Discussion}

Under the precondition of adequate neurogenic stimulation, dilatation of the penile arteries, particularly of the aa. profundae penis, relaxation of the cavernosal sinusoids and constriction or compression of the penile veins results in an erection with full rigidity [6]. The apparent hemodynamic changes caused by neurogenic stimulation correspond to those seen after intracavernous injection of vasoactive substances [8].

Our Doppler tests performed on the a. profunda penis show that the intracavernous injection of vasoactive substances causes a strong increase in blood flow within $30 \mathrm{sec}$. This flow increase reaches a maximum after 4-6 min, but is no longer detectable by Doppler ultrasonogaphy $20 \mathrm{~min}$ after a complete erection has been achieved (Fig. 2). This, together with blood gas analysis, which deteriorates with the duration of the erection (Fig. 3 ), gives the characteristic picture of a low-flow or even no-flow priapism [7].

This condition is likely to have its origin in a maximal relaxation of the intracavernosal smooth muscles. This maximal relaxation can be interrupted by intracavernosal injection of alpha-sympathomimetics, as our results have been able to demonstrate. When, however, pronounced ischemic changes associated with a low tissue $\mathrm{pH}$ are present in the corpus cavernosum as a result of a persisting erection, it seems that the low $\mathrm{pH}$ blocks the effect of the alpha-receptor stimulant. This condition calls for an invasive procedure with puncture of the corpora cavernosa and aspiration of ischemic blood. The introduction of a glandulocavernosal shunt was not necessary in our patients.

The absence of subjective and objective adverse cardiovascular effects to the intracavernous injection of metaraminol ( 2.0 and $2.5 \mathrm{mg}$ ) is due on the one hand to the low doses used and, on the other, to preselection of the population as patients with severe cardiovascular disease were excluded. Possible untoward effects affecting the heart, which was noted in the one patients of group 6 , justify rigid preselection criteria, all the more so, since severe paroxysmal hypertension and allergic reactions following intravenous doses of metaraminol have been described [1].

The prolonged erections during diagnosis and therapy did not cause any of the patients to reject or dicontinue auto-injection therapy. The three cases of prolonged erections under home treatment occurred during the first 6 months in which this kind of therapy was used at our hospital. Since, on the basis of this experience, we now warn our patients not to apply more than one auto-injection per day, even if the injection appears to be unsuccessful, we have received no further reports on persisting erections during home treatment within the last 17 months.

\section{Conclusion}

Prolonged erections resulting from intracavernous injection of vasoactive substances should be stopped after $3 \mathrm{~h}$ and in no case be allowed to persist for more than $6 \mathrm{~h}$, as they involve the risk of ischemic damage to the cavernous tissue with resulting irreversible erectile impotence. A simple method is the intracavernous injection of $2 \mathrm{mg}$ metaraminol. When repeated injection of $1 \mathrm{mg}$ metaraminol fails to produce flaccidity in the case of persisting rigidity, puncture and aspiration of the corpora cavernosa are required.

The use of vasoactive substances for diagnostic and therapeutic purposes in patients with erectile dysfunction as well as the administration of antagonistic alpha-sympathomimetics require careful preselection of the population, cooperation of the individual patient, and the full responsibility of the treating physician, who must be aware that he is working with highly potent drugs.

\section{References}

1. Altwein JE, Bähren W, Stief CG, Thon W (1987) Rationelle Diagnostik und Stellenwert der SKAT-Testung. In: Proceedings of the 10th International Symposion, Ludwig Boltzmann Institut, Wien, pp $345-350$

2. Brindley GS (1983) Cavernosal alpha-blockade: new technique for investigating and treating erectile impotence. $\mathrm{Br} \mathrm{J}$ Psych 143:332- 337

3. Brindley GS (1984) A new treatment for priapism. Lancet ii: $220-221$

4. Ginestie JF, Romieu A (1977) L'exploration radiologique de l'impuissance. Maloine, Paris

5. Jevtich MJ (1984) Non-invasive vascular and neurogenic tests in use for evaluation of angiogenic impotence. International Angiology $3: 225-232$

6. Juenemann KP, Luo J-A, Lue TF, Tanagho EA (1986) Further evidence of venous outflow reduction during erection. Br J Urol $58: 320-324$

7. Juenemann KP, Lue TF, Abozeid M, Hellstrom WJG, Tanagho EA (1986) Blood gas analysis in drug-induced penile erection. Urologia Internationalis 41:207-211

8. Lue TF. Hricak H, Schmidt RA, Tanagho EA (1986) Functional evaluation of penile veins by cavernosography in papaverine-induced erection. J Urol 135:479-482

9. Robinette MA, Moffat MJ (1986) Intracorporal injection of papaverine and phentolamie in the management of impotence. $\mathrm{Br}$ J Urol 58:692-695

10. Sidi AA, Cameron JS, Duffy LM, Lange PH (1986) Intracavernous drug-induced erections in the management of male erectile dysfunction: experience with 100 patients. J Urol 135:704-706

11. Stief CG, Bähren W, Gall H, Scherb W, Gallwitz A, Altwein JE (1986) Schwellkörper-Autoinjektionstherapie (SKAT): erste Erfahrungen bei erektiler Dysfunktion. Urologe A 25:63-66

12. Virag R (1982) Intracavernous injection of papaverine for erectile failure. Lancet $\mathrm{i}: 938$

13. Zorgniotti AW, Lefleur RS (1985) Auto-injection of the corpus cavernosum with a vasoactive drug combination for vasculogenic impotence. J Urol 133:39-41 